\title{
Population Difference in foraging behaviour of Nandus nandus (Hum-Buch)
}

\author{
Sheenaja. K. K \\ Animal Behaviour Research Laboratory; Department of Zoology; S.H College; Thevara; Kerala.
}

\begin{abstract}
Nandus nandus collected from regions of high and low predation and its foraging behaviour was investigated. A strong correlation in the foraging assay with that of sites from fish emerged. These habitats differ in physical structure and resident prey communities so related difference in searching behaviours for effective foraging. Laboratory feeding trials were conducted in aquaria containing T maze is used by Nandus nandus to study their habitat specific foraging rates. Leaf fish from high-predation areas were faster in seeking food than those fish from low predation. These results suggest personality traits are influenced by population specific ecological variables and may have future fitness consequences in wild population. Foraging skill plays a major behaviour that influences the fish in wild. These differences in searching tactics translate into differences in habitat-specific foraging efficiency. So here this behavioural measure is studied in detail before planning post larval release technology in this LnRT fish. Hence this work will be in sight to conservation of this fish from LnRt category.
\end{abstract}

Key words: Nandus nandus ; predator; foraging,conservation

\section{Introduction}

Maintenance and preservation of biodiversity along with other biotic resources are a prerequisite for the well-being of even human beings [1] . Over exploitation of fish resources, coupled with habitat destruction result in shrinkage of fish population [2]. The only viable alternative is to conserve and propagate native species, which are at the verge of extinction. Induced breeding and re-introduction of hatchery reared larvae into their natural habitat are the usual techniques employed for the rehabilitation of threatened and endangered species. However, captive reared individuals frequently suffer mortality shortly after release [3]. Annually billions of young fishes are released from hatcheries into the natural water bodies, yet the majority of these fish perish, incapable to cope up with the new environment [4]. Environmental effects on hatchery rearing may result in the development of behaviour patterns that are not akin to the behaviour of the conspecifics living in the wild [5] .The environment during early life stages has been suggested to have a strong influence on subsequent behaviour, which may not be easily modified during later life [6].

Understanding the behavioural ecology of an organism is essential in current scenario where many animals being decimated or forced to get extinct due to unbridled human intervention. Behavioural ecology helps to find the change in the population structure as well as to predict the future predispositions of species concerned. Knowledge from the field of foraging ecology, reproductive ecology as well as the understanding of cognitive abilities of fishes are essential for developing strategies to control the process of extinction. Animals use different behavioural strategies to maximize their fitness in natural environments. Learning and memory is critical, allowing organism to respond to environmental changes flexibly and rapidly. To forage efficiently animals need accurate information about the quality of foraging patches. In fish, spatial memory can enhance foraging rate [7], territory defence [8] and predator avoidance [9]. In mammals and birds, the hippocampus plays a crucial role in spatial memory [10]. Studies suggest that fish are capable of spatial learning and can use information in different environments [11] . The ability of individuals to adjust energy expenditure while foraging is likely to influence fitness [12] because foraging determines the intake of resources that are expended on fitness related activities.

Nandus nandus (Hum-Buch) is having high potentional in exporting and fetching an average price of 0.75 US \$ .Based on IUCN categorization [13] this fish was analysed to find out status of threat. Nandus nandus (Hum-Buch) is enlisted under the low-Risk near threatened (LnRt) category[14].Considering LnRT status of this fish and its food and ornamental value its highly desirable to conserve and native species which is still in greater demand by consumers and ornamental fish market. So a study foraging behaviour is indeed as a preliminary step to generate more information on their biology, breeding patterns and to promote the post induced breeding operation.

\section{Study Subjects}

\section{Materials And Methods}

Adult females are normally fuller-bodies and larger than comparably-aged males. Our observations suggest that females also possess a more conical, pointed and upward bend mouth than males. During breeding season a prominent black bloch is noticed in caudal peduncle of female .During breeding season milt oozes from the males when belly is squeezed and females with bulged belly full of ripe ova. 
The Nandus nandus used from two sites from kodungaloore (High predation site) and Pullut (Low predation site) in this study were acclimatised to the laboratory condition of housed in 90-cm-long aquaria. Each aquarium was equipped with a power filter, plastic plants, gravel, and rocks. Water was maintained at approximately $26^{\circ} \mathrm{C}, \mathrm{pH} 7$, and overhead fluorescent lights provided 12:12 h light:dark. Fish were fed live food once per day. Although there are differences in the average standard length between fish from high- and lowpollution sites, we minimized this by deliberately testing fish of approximately the same size from each population (mean standard length $40.7 \mathrm{~mm}$ ) and of the similar age group.

Assay for feeding behaviour:

At 1600 hours on day 1, single fish were placed into their own $38 \mathrm{~L}$ aquarium. The fish were fed with live small climbing perch, at 1630 hours on day 1 and at 0830hours on day 2. At 1200 hours on day 2, fish were again fed with live small five climbing perches and the number of bites taken in the 300s and time taken to reach the reward following the release of Nandus nandus into the aquarium were counted and recorded. Simple T maze was used, reward arm was adjusted such that experimental fish can easily go through but rewarded fish can't come out.

\section{Result}

As there was a significant effect in the mean time taken to locate the patch and begin feeding shows a marginal effect of predator regime $(\mathrm{F} 1,40=3.70, \mathrm{p}=.051)$, suggesting that over the period of the experiment lowpredation fish were faster to locate the rewarded patch and begin eating than high-predation fish. Examination of Figure 1 shows that low-predation fish had reached their minimum foraging latency, whereas high-predation fish only reach a similar reward with maximum time.

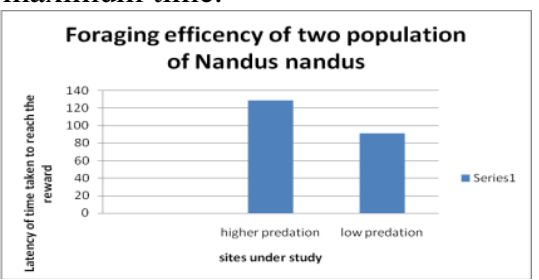

Figure I: Population difference in foraging efficiency of Nandus nandus collected from high predation and low predation site

As there was a significant effect in the mean number of bites taken after locating the patch and begin feeding shows a marginal effect of predator regime $\quad(\mathrm{F} 1,40=5.13, \mathrm{P}=0.048)$, suggesting that over the period of the experiment mean number of bites taken after locating the patch was high for high-predation fish and lowpredation fish were slow in taking mean number of bites. Examination of Figure ii shows that low-predation fish had reached their minimum number of bites taken after locating the patch, whereas high-predation fish taken maximum mean number of bites taken after locating the patch.

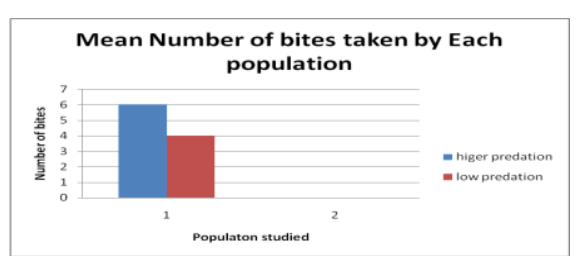

Figure II Population difference in mean number bites taken by Nandus nandus collected from high predation and low predation site.

\section{Discussion}

Few studies have attempted to investigate the fitness consequences of Nandus nandus populations occupying a range of habitats. The analysis in this paper revealed a strong relationship between foraging behaviour and predation regime. While there is an overall effect of predation pressure across two populations, we did observe differences between the streams. There are a number of possible explanations for the observed differences in the behaviour of the fish between rivers primarily pertaining to the larger ecological differences that occur at this scale. We deliberately chose streams and sites within streams to minimize the differences in geomorphological structure and in-stream fauna, but clearly the rivers were not identical.

Nandus nandus varied with predation regime. The Nandus nandus did learn the maze task, as indicated by the decrease in errors and time to find the reward as their experience increased. However, performance in the maze test indicated both between and within-population variation in the speed and accuracy of decision making. There was a detectable effect of predation regime on the other variables of interest (i.e. proportion of errors made and time to reward). High predation fish forage more slowly than low predation river fish because they do not have so many variables to pay attention to, allowing them to learn this relatively simple spatial task at equal rates.

A possible explanation for these observed differences in foraging rate is divided attention. Animals continually receive information about their environment, and must filter this information in order to focus on 
those aspects most important to survival [15] . The ability of an animal to successfully perform a given task can be affected by the amount of attention being focused simultaneously on other activities [15] . For example, three-spined sticklebacks [16] and guppies, engaged in more complex foraging tasks are more vulnerable to predation, and are preferred targets for predators [17], presumably because their attention is divided between foraging and predator vigilance. Similarly, denser swarms of Daphnia decrease foraging efficiency of threespined sticklebacks due to the confusion effect, whereby predators find in harder to target any one individual the denser a swarm of prey becomes [18].

Furthermore, a study found that fish selectively bred to have a lateralized brain (i.e. they used different halves of the brain to process particular tasks) had a foraging advantage over non-lateralized individuals when a predator was present, and this was attributed to lateralized fish being better able to process multiple sources of information, processing each task with one brain hemisphere [19] . In my system, it may be expected that high predation river fish ie clear river have several activities to divide their attention amongst; they must be vigilant for predators and pay attention to their spatial location to avoid becoming moved to unfavourable areas by water currents or exploration. This would leave less attention for locating profitable feeding sites, and may explain why high predation river fish take longer to learn the spatial foraging task presented here. Low predation river fish ie polluted river may not have to expend the same amount of attention on predator detection, enabling them to devote more attention to other tasks, such as locating feeding sites, possibly translating to faster foraging rate in the present experiment. In contrast to this in polluted environments, fish may not have so many tasks to divide their attention between. They will not be relocated to unfavourable areas by current or exploration, and it is expected that they have no stable local landmark cues to aid navigation. Thus, high predation fish forage more slowly than low predation river fish because they do not have so many variables to pay attention to, allowing them to learn this relatively simple spatial task at equal rates.

In conclusion, I have found the foraging ability difference among the two populations studied. Interaction between river habitat and predation pressure influences foraging rate. This suggests that although they are linked, foraging have differences, and may be shaped in the same way by the same ecological factors. It also highlights the complex nature of natural habitats, and shows how multiple ecological factors can interact to affect behaviour.

Future prospects: Attempts to counteract hatchery-related behavioural deficiencies have utilized intensive training programmes shortly before the hatchery fishes are released to nature. Induced breed Nandus nandus and application of hatchery enrichment technique can be adopted to conserve it from LnRt category.

\section{Refrence}

[1] Lakra, W.S., Singh, A.K. and Mahanta P.C. (2009). (eds.) In Fish genetic resources, Narendra Publishers ,New Delhi, India.

[2] Pandey, A.K. and Das, P. (2002). Ichtyo biodiversity conservation of sustainable production, Fishing chimes., 22, (5) 14-24.

[3] Snyder, N. F. R., Derrickson, S. R., Beissinger, S. R., Wiley, J. R., Smith, T. B., Toone, W.D. and Miller, B. (1996). Limitations of captive breeding in endangered species recovery. Conservation Biology .,10, 338-348.

[4] Brown, C. and Laland, K. (2001). Social learning and life skills training for hatchery reared fish. Journal of Fish Biology., 59, 471493.

[5] Keeley, E. R. (2001). Demographic responses to food and space competition by juvenile steelhead trout. Ecology .,82, 1247-1259.

[6] Martin, S. W., Viola, A. E. and M. L. Schuck. (1993). In Investigations of the interactions among hatchery reared summer steelhead, rainbow trout, and wild spring Chinook salmon in southeast Washington, Washington Department of Wildlife, Report \# 93-4.

[7] Hughes, R.N. and Blight, C.M. (1999). Algorithmic behaviour and spatial memory are used by two intertidal fish species to solve the radial maze. Anim Behav., 58(3):601-613.

[8] Lamanna, J.R. and Eason, P.K. (2003). Effects of landmarks on territorial establishment. Anim Behav., 65:471-478. doi:10.1006/anbe.2003.2095

[9] Markel, R.W. (1994). An adaptive value of spatial learning and memory in the blackeye goby, Coryphopterus nicholsi. Anim Behav., 47:1462-1464. doi:10.1006/anbe.1994.1194.

[10] Healy, S.D., De Kort, S.R. and Clayton, N.S. (2005). The hippocampus, spatial memory and food hoarding: a puzzle revisited. Trends Ecol Evol., 20:17-22. doi:10.1016/j.tree.2004.10.006.

[11] Odling-Smee, L. and Braithwaite, V.A. (2003). The influence of habitat stability on landmark use during spatial learning in the threespined stickleback. Anim Behav., 65: 701-707.

[12] Stephens, D.W. and Krebs, J.R. (1986). Foraging Theory. Princeton University Press, Princeton, New Jersey.

[13] Anon. (1998). Proceedings of worshop on germplasm inventorisation and gene banking of fresh water fishes. NBFGR, Lucknow.

[14] Ramachandandran, A.(2002).Fresh water indigenous ornamental fish resource in kerala and their prospects for international marketing In Boopendranth,M.R(ed)Riverine and Reservoir fisheries of india,109-135.

[15] Dukas.(2002). Behavioural and ecological consequences of limited attention, Philosophical Transactions of the Royal Society of London Series B 357, 1539-1547.

[16] Milinski, M. (1984). A predators' cost of overcoming the confusion-effect of swarming prey. Anim Behav., 32, 1157-1162.

[17] Krause, J. and Godin, J.J. (1996). Influence of prey foraging posture on flight behavior and predation risk: predators take advantage of unwary prey. Behavioural Ecology., 7, 264-271.

[18] Ohguchi, O. (1981). Prey density and selection against oddity by three-spinedsticklebacks. Advances in Ethology., 23, 1-79.

[19] Dadda, M. and Bisazza, A. (2006). Does brain asymmetry allow efficient performance of simultaneous tasks? Anim Behav., 72, 523-529. 